\title{
Kuzey Atlantik Salınımının Çanakkale Rüzgâr Enerji Potansiyeline Etkisinin İncelenmesi
}

\author{
Zeliha Semerci ${ }^{1}$, Bahtiyar Efe ${ }^{2 *}$ \\ 1 Samsun Üniversitesi, Havacılık ve Uzay Bilimleri Fakültesi, Meteoroloji Mühendisliği Bölümü, İstanbul, Türkiye (ORCID: 0000-0000-0000-0000), zelihasemerci64@ gmail.com \\ ${ }^{2 *}$ Samsun Üniversitesi, Havacılık ve Uzay Bilimleri Fakültesi, Meteoroloji Mühendisliği Bölümü, İstanbul, Türkiye (ORCID: 0000-0001-5604-7068), bahtiyar.efe@ samsun.edu.tr
}

(İlk Geliş Tarihi 29 Ağustos 2020 ve Kabul Tarihi 15 Ekim 2020)

(DOI: 10.31590/ejosat.787768)

ATIF/REFERENCE: Semerci, Z. \& Efe, B. (2020). Kuzey Atlantik Salınımının Çanakkale Rüzgâr Enerji Potansiyeline Etkisinin İncelenmesi. Avrupa Bilim ve Teknoloji Dergisi, (20), 374-380.

$\ddot{\mathrm{O} z}$

Kuzey Atlantik Salınımı'nın (KAS), rüzgâr enerji potansiyeline etkisinin de diğer meteorolojik parametrelerde olduğu gibi mevsimsel olarak değiştiği görülmektedir. Kış mevsiminde KAS endeksinin pozitif fazı hâkim iken ortalama rüzgâr ve yıllık üretim değeri tarafsız ve negatif faza göre düşüktür. Kış mevsiminde rüzgâr enerji potansiyeli için tarafsız ve negatif faz arasında belirgin bir değişim söz konusu değildir. İlkbahar mevsiminde ise KAS endeksinin negatif fazı hâkim iken ortalama rüzgâr ve yıllık üretim değerinde belirgin düşüş söz konusudur. İlkbahar Mevsiminde KAS endeksinin pozitif fazı hâkim iken ortalama rüzgâr hızında ve yıllık üretim değerinde artı̧ söz konusudur fakat artış miktarı endeksin negatif fazına dayalı düşüş kadar yüksek değildir. İndeksin pozitif fazında üretilen enerji negatif fazında üretilen enerjiye göre daha fazladır. KAS'ın etkisi yaz mevsiminde ülkemiz için asgari düzeydedir, bu durum rüzgâr enerjisinde de kendisini göstermektedir. Yaz mevsimi için KAS endeksinin negatif ve pozitif olduğu iki durumda da ortalama rüzgâr ve yıllık üretim değeri nötr durumdan fazladır. Nihayetinde KAS endeksinin yaz mevsiminde rüzgâr enerjisine etkisi azdır. Sonbahar mevsiminde KAS endeksinin pozitif olduğu durumda yıllık üretim miktarı azami düzeyde, negatif sonbaharlar için yıllık üretim miktarı nötr faza göre düşüktür. Sonbahar mevsimi için KAS endeksinin pozitif, nötr ve negatif fazlarında üretim miktarında pozitiften negatife doğru belirgin bir azalma söz konusudur. KAS fazları ile mevsimlik ortalama rüzgar şiddeti değerleri arasındaki ilişki incelendiğinde, yüksek korelasyon değerlerinin pozitif kış ile pozitif ve negatif yaz dönemlerinde olduğu görülmüştür.

Anahtar Kelimeler: Kuzey Atlantik Salınımı, Rüzgâr Enerjisi, Weibull, WAsP, Çanakkale

\section{Investigation of the Effect of North Atlantic Oscillation on Wind Energy Potential of Çanakkale}

\begin{abstract}
North Atlantic Oscillation has an impact on wind energy potential changing seasonally as in other meteorological parameters. While the positive phase of the NAO index prevails in winter, the average wind and annual production value is lower than the neutral and negative phase. There is no significant change between neutral and negative phases for wind energy potential in winter. In the spring season, while the negative phase of the NAO index is dominant, there is a significant decrease in the average wind speed and annual energy production value. While the positive phase of the NAO index prevails in the spring season, there is an increase in the average wind speed and annual production value, but the amount of increase is not as high as the decrease based on the negative phase of the index. The effect of NAO is minimal for our country in the summer season, and this also shows itself in wind energy. In both cases where the NAO index for the summer season is negative and positive, the average wind and annual production value is higher than the neutral situation. Ultimately, the NAO index has a slight effect on wind energy in summer. In case the NAO index is positive in autumn, the annual production amount is at maximum level, and for negative autumn, the annual production amount is lower than the neutral phase. There is a significant decrease in the production amount from positive to negative in the positive, neutral and negative phases of the NAO index for the autumn season.
\end{abstract}

Keywords: North Atlantic Oscillation, Wind Energy, Weibull, WAsP, Çanakkale.

\footnotetext{
*Sorumlu Yazar: bahtiyar.efe@samsun.edu.tr
} 


\section{Giriş}

Son yilların temel sorunlarından biri olan küresel isınma ve iklim değişikliğinin ana sebepleri insan kökenlidir (IPCC, 2013). Buharlı makinaların icadı, sanayileşme faaliyetleri, teknolojik gelişmeler, dünya nüfusundaki artış, refah seviyesinin yükselmesi enerjiye duyulan ihtiyacı artırmıştır ve artırmaktadır. Daima artan enerji ihtiyaç ve fosil yakıtların tüketiminden ortaya çıkan tahribatı azaltmak gayesiyle uluslararası çalışmalar ile daha temiz ve dönüştürülebilir olan yenilebilir enerji (rüzgâr, güneş, biokütle, dalga vb.) kaynakların kullanımları artmıştır (Karabulut, 1999). Global olarak toplam enerji üretiminde yenilenebilir enerji kaynak payı 2006 y1lında \%19 iken, bu oranın 2011 yılında \%20'ye yükselmiştir (IEA, 2013). Türkiye rüzgâr gücünden elektrik üretim potansiyeli yüksek bir ülke olup 83.000 MW (yıllık 300 milyar kWh) üretim gücüne sahiptir. Türkiye'de rüzgâr enerjisinden elektrik üretimi giderek artmaktadır. Türkiye'de rüzgâr enerjisinden elektrik üretimi 2016 yllında 15.517 GWh, 2017 yılında 17.904 GWh, 2018 yilında 19.882 GWh'dır (IEA, 2018). Çanakkale bölgesi Rüzgar Enerji Potansiyel Atlası'na (REPA) göre Türkiye'de en yüksek rüzgâr potansiyeline sahip bölgesidir (Şekil 1). Çanakkale'de kurulu güç 3.964 MW, yıllık elektrik üretimi $21.107 \mathrm{GWh}$, y1llık tüketimin \%8,26'dır (Türkiye Enerji Atlas1, 2020).

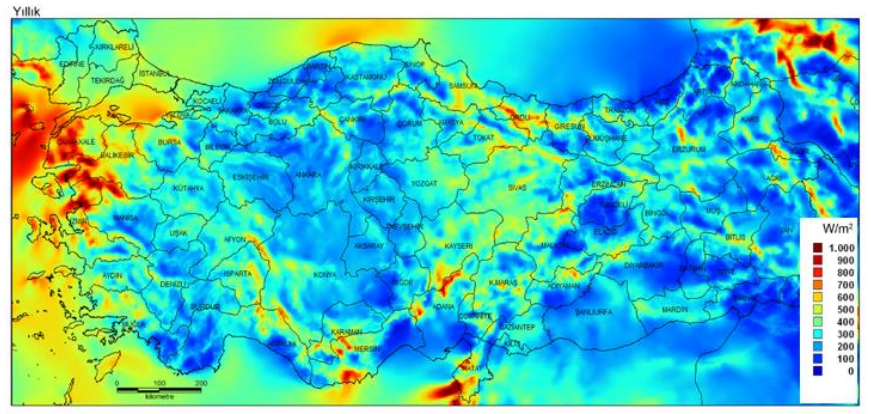

Şekil 1: Türkiye rüzgâr enerji potansiyel atlası (EIGM, 2020).

Rüzgâr zamana ve hava koşullarına bağlı olarak değişiklik gösterir. Rüzgârın ortalama mevsimsel ve günlük değişkenliği iyi bilinmektedir ve rüzgâr hızı güvenilir bir şekilde saatler veya günler öncesinden tahmin edilebilir. Rüzgâr değişkenliğinin az bilinen bir yönü, rüzgâr hızlarının bir yıldan diğerine nasıl ve neden değiştiğidir. Bu tür düşük salınımlı değişkenlik hakkındaki bilgi, rüzgâr türbinlerinden uzun vadeli güç üretiminin öngörülmesi için önemlidir (Sailor ve ark., 2000). Atmosferdeki küresel ve bölgesel ölçekli hava sirkülasyonları, bölgesel iklim anomalilerinin oluşmasını sağlar (Yetmen, 2006). Bu küresel ölçekli sirkülasyonlardan bir tanesi de Kuzey Atlantik Salınımı (KAS)'dır. KAS, etki ettiği geniş ölçekte iklime doğrudan veya dolaylı bağlı ekonomik faaliyetleri etkilemektedir (Yetmen, 2006). KAS, İzlanda (alt-kutbi bölge) civarında bulunan alçak basınç merkezi ile Azor Adaları (alt-tropik bölge) civarında bulunan yüksek basınç merkezi arasındaki atmosferik basınç salınımıdır (Şekil 2). Farklı karakteristiğe sahip iki basınç merkezi arasında meydana gelen rüzgârlar sadece Kuzey Atlantik'te değil, Kuzey Amerika'dan Avrupa ve Kuzeybatı Asya'ya uzanan bölgede; yağış, basınç ve sıcaklıkları etkilemektedir. Basınç merkezlerinin ikisi de normalden daha güçlü durumdaysa; İzlanda Alçak Basınç Merkezinin merkez değeri normalden daha küçük, Azor Yüksek Basınç Merkezi'nin merkez değeri normalden daha yüksek ise KAS endeksi pozitiftir. Azor YBM'nin bulunduğu e-ISSN: 2148-2683 bölgede ABM; İzlanda ABM'nin bulunduğu bölgede YBM mevcutsa KAS endeksi negatiftir. KAS endeksi Wallace \& Gutzler (1981) tarafından tanımlanmıştır. Kuzey Atlantik Salınım endeksi ile Türkiye yağışlarının ve sıcaklıklarının farkları arasında ters bir ilişki olduğunu ve KAS indisinin pozitif evresi Türkiye'de yağışların azalmasına ve sıcaklıkların düşmesine yol açarken, negatif evresinde yağışlar ve sıcaklıkların artmasına yol açtığı görülmektedir (Türkeş \& Erlat, 2003).

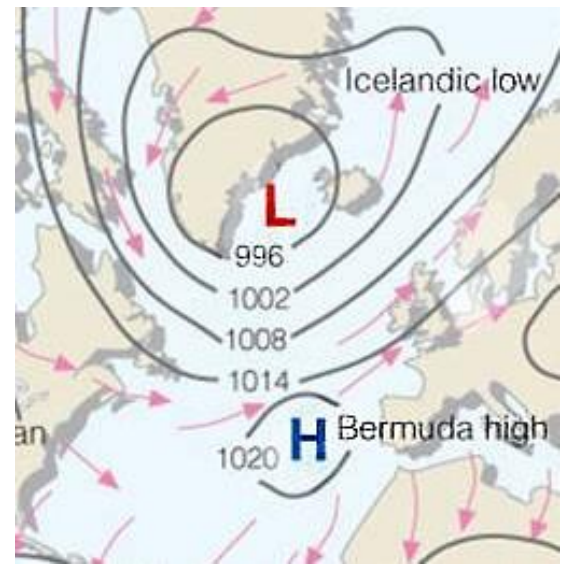

Şekil 2: KAS’’ etkileyen basınç sistemleri (NCSU, 2020)

Rüzgâr üzerine çalışmalar farklı alanlarda gerçekleştirilmektedir. Bazı çalışmalar rüzgar enerjisi potansiyelini incelerken (Özdemir ve ark., 2015), bazı çalışmalar rüzgar enerjisi tahmini (Efe ve ark., 2012) ile ilgilenmektedir. KAS'ın rüzgâr enerjisine etkileri ile ilgili çalışmalar da mevcuttur. Brayshaw ve ark. (2011) yaptıkları çalışmada; KAS'ın üç farklı fazının İngiltere için rüzgâr enerjisi potansiyeline etkisini incelemişlerdir. Çalışmada aylık ortalama KAS verileri ABD'nin Ulusal Okyanus ve Atmosfer İdaresi'nden (NOAA) elde etmişlerdir. Saatlik ortalama $10 \mathrm{~m}$ yükseklikten ölçülen rüzgâr hızı verilerini Met Office Integrated Data Archive System (MIDAS) veri kümesinden elde etmişlerdir. Çalışma Great Dun Fell ve Stornoway Havalimanı için uygulanmış, verileri birbirinden tamamen bağımsız olarak değerlendirilmiştir. Her KAS kategorisindeki rüzgâr hızı dağılımı, rüzgâr hızlarını temsil etmek için yaygın olarak kullanılan bir dağılım olan Weibull dağılımına benzemektedir. Ayrıca rüzgâr hızları genellikle yüksek KAS sırasında düşük KAS'dakinden daha yüksektir. Saatlik ortalama güç üretimi, günlük ortalama güç üretimi ve daha uzun süreler (1030 gün) için güç üretimlerine KAS'1n etkisi incelenmiştir. KAS durumunun dağılımlar üzerinde belirgin ve istatistiksel olarak anlamlı (\%99 güven aralığı) bir etkisi olduğu sonucuna varmışlardır (Brayshaw ve ark., 2011). Zubiate ve ark. (2016) yılında yaptıkları çalışmada kış mevsiminde KAS endeksi ile Batı Avrupa'daki rüzgar hızı arasındaki ilişkiyi incelemiştir. Kış mevsiminin seçilmesinin nedeni, KAS'ın etkisinin Avrupa'da en çok kış mevsiminde hissedilmesidir. Çalışmada 10 metre yükseklik için hazırlanmış, 3 saatlik zaman çözünürlüğüne sahip, ECMWF Reanaliz verisi (ERA-Interim) rüzgar veri setleri kullanılmış; veriler logaritmik bir profil kullanılarak $80 \mathrm{~m}$ yüksekliğindeki tipik bir rüzgar türbini göbeği yüksekliğine ekstrapole edilmiştir. Ocak 1979 yılından başlayan rüzgar verileri Şubat 2013'e kadar sürmektedir. KAS endeksi pozitif ve negatif olarak ikiye ayrılmıştır. Spearman rank korelasyonu kullanılarak aylık KAS endeksleri ile ortalama aylık rüzgar hızları arasındaki ilişki değerlendirilmiştir. Bu çalışmanın kapsadığı 35 yıllık 104 kış ayından 55'inde pozitif KAS endeksi ve 49'unda negatif KAS endeksi görülmüştür. Pozitif KAS endeksi olan tüm aylar için ortalama rüzgar hızı Kuzey Avrupa üzerinden ve Güney Avrupa 
üzerindeki akışı zayıflatmaktadır. Öte yandan, negatif KAS kışları, Kuzey Atlantik ve Batı Avrupa sektörlerinin çoğunda daha düşük ortalama rüzgar hızları içermektedir. İber Yarımadası ve Batı Akdeniz'de daha güçlü rüzgar hızları mevcuttur. Güçlü negatif KAS endeksi ile aylık ortalama rüzgar hızları İber Yarımadası ve Akdeniz bölgesinde zayıf negatif korelasyonlar, Güney Fransa'da ve Birleşik Krallık'ın güney kesiminde zayıf pozitif korelasyonlar oluşturmuştur (Zubiate ve ark., 2016). Bustamente ve ark. (2013) yılında yaptıkları çalışmada; İber Yarımadası'nın kuzey doğusunda rüzgar enerjisi üretimi ile KAS arasındaki ilişkiyi incelemişlerdir. Bölgede seçilen üç rüzgar çiftliğinde (Aritz, El Perdón ve Alaiz) kaydedilen rüzgar hızı ve rüzgar enerjisi üretim verileri çalışmada kullanılmıştır. Rüzgar verileri, rüzgar çiftliği türbinlerinin göbek yüksekliğinde, 30 ile $45 \mathrm{~m}$ arasında bulunan anemometrelerden de toplanmıştır. Rüzgar ve rüzgar enerjisi kayıtları, Haziran 1999'dan Mayıs 2003'e kadar uzanır. Çalışma KAS ve bölgesel rüzgar alanı arasındaki bağlantının en güçlü olduğu Eylül-Mart ayları arasına odaklanmıştır. Çalışma, yıllık ve on yıllık zaman ölçeklerinde rüzgarla doğrusal ilişki de dahil olmak üzere rüzgar gücünün uzun vadeli değişimleriyle ilgili bazı yönleri açıklığa kavuşturmaya yardımcı olabilecektir. Çalışma sonucunda anlaşılmıştır ki, rüzgar enerjisi üretim kayıtları olmayan ancak rüzgar hızı ölçümlerinin mevcut olduğu yerlerde de rüzgar enerjisi üretiminin tahmini, KAS endeksi ile rüzgar arasındaki ilişkiye dayandırılarak yapilabilir (Bustamente ve ark., 2013).

Çeşitli atmosferik olayların sıcaklık (Efe ve ark., 2020), yağış (Efe ve ark., 2019) etkisi çeşitli çalışmalarda incelenmiştir. Fakat atmosferik salınımların Türkiye' deki rüzgâr enerjisi potansiyeline etkisi yeterince incelenmemiştir. Bu çalışmanın amacı KAS'ın Çanakkale bölgesi rüzgar istatistiklerine ve rüzgar enerjisi potansiyeline etkisini incelemektir. Bu amaçla, 1990 - 2019 yıllarını kapsayan aralıktaki KAS fazları için, ortalama rüzgar şiddeti değerleri temin edilmiş ve KAS'ın rüzgar enerjisi potansiyeline etkisi incelenmiştir. Çalışmanın, ikinci bölümünde materyal ve metot, üçüncü bölümünde araştırma sonuçları ve tartışma, dördüncü bölümünde ise sonuç kısmı yer almaktadır.

\section{Materyal ve Metot}

\subsection{Materyal}

Çalışmada, Meteoroloji Genel Müdürlüğü (MGM) 'nden alınan, Çanakkale Meteoroloji İstasyonuna ait, 1990 - 2019 yıllarını kapsayan dönem için saatlik ortalama rüzgâr verisi kullanılmıştır. Rüzgâr verileri 10 dakikalık ölçümlerin ortalaması şeklinde olup, 10 metre yükseklikten ölçülmüştür. Çanakkale istasyonunun seçilmesinin birinci nedeni, REPA'ya göre en yüksek rüzgâr enerjisi potansiyeline sahip olmasıdır (REPA, 2020. İkinci neden ise, Türkiye'deki rüzgâr enerjisi santrallerinin yaklaşık \%5'inin bu ilimizde kurulu olmasıdır (TUREB, 2019). Çanakkale, Kuzeybatı Anadolu' da aynı isimli boğazın en dar kıyısında yer alır. İl genel olarak $25^{\circ} 40^{\prime}-27^{\circ} 30^{\prime}$ Doğu meridyenleri ile $39^{\circ} 27^{\prime}-40^{\circ} 45^{\prime}$ Kuzey enlemleri arasında bulunmaktadır. Çanakkale İli, batısında ve güneybatısında Ege Denizi, kuzeyinde Marmara Denizi ve Tekirdağ, kuzeybatısında Edirne ve Doğu ve güneydoğusunda Balıkesir ile çevrilidir (Şekil 3). En yüksek dağı Kaz Dağı'dır. Çanakkale iklimsel olarak Karadeniz ve Akdeniz iklimleri arasında Marmara geçiş iklimin güneybatısında yer alır. Sicaklık bakımından Marmara geçiş ikliminde, yağış rejimi ise Akdeniz yağış rejimidir. Bölgenin engebeli yapısı iklim özelliklerinin dar alanlarda değişkenlik göstermesine sebep olur. Thornthwaite iklim sınıflandırmasına göre Çanakkale yarı nemli bir iklime sahiptir (Türkeş, 2011).

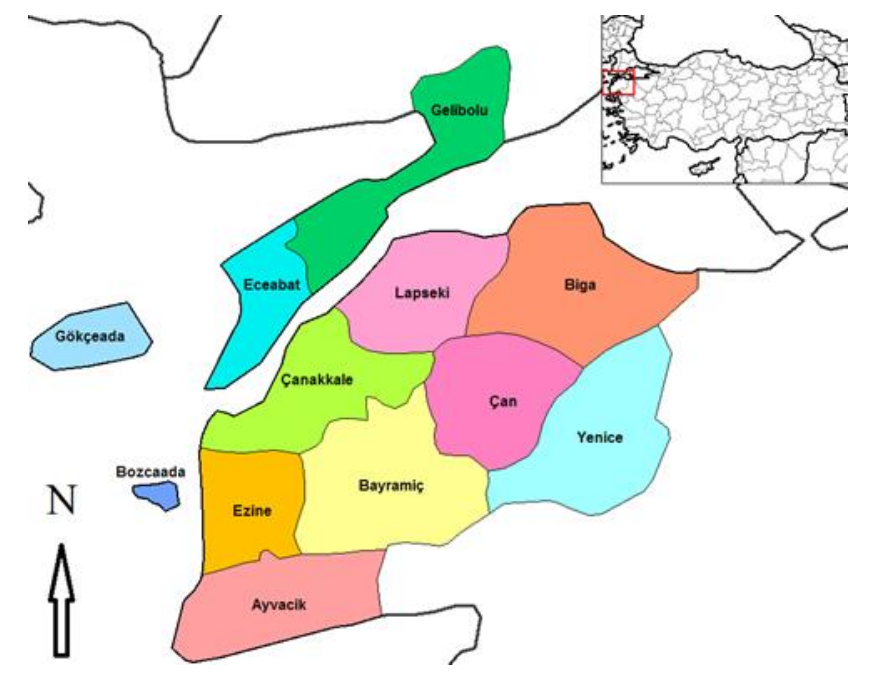

Şekil 3: Çanakale il haritası ve Türkiye'deki konumu (Türkiye Rehberi, 2020)

KAS fazlarını belirlemek için, Climate Prediction Center 'dan alınan KAS endeks verileri kullanılmıştır (NWS, 2020). 1990-2019 yılları arasında endeks mevsimsel olarak incelenmiş;

- Endeksin 0'a en yakın olduğu, yani nötr fazda olduğu, her bir mevsim için 4 mevsimsel veri seti (KAS'ın etkisinin neredeyse hiç olmadığı),

- Endeksin azami olduğu, yani pozitif fazda olduğu her bir mevsim için 4 mevsimsel veri seti,

- Endeksin asgari olduğu, yani negatif fazda olduğu her bir mevsim için 4 mevsimsel veri seti

oluşturulmuştur. Böylelikle her bir mevsim için birer y1llık 3 veri seti oluşturulmuştur. Her bir KAS fazı için mevsimlere göre kullanılan rüzgâr verilerinin ait olduğu yıllar, Tablo 1'de gösterilmiştir.

. Tablo 1. Her bir mevsim ve KAS sınıfı için kullanılan y1llar

\begin{tabular}{|l|c|c|c|}
\hline & Pozitif KAS & Negatif KAS & Nötr KAS \\
\hline Kış & 1991,1995, & 1996,1997, & 2001,2003, \\
& 2012,2015 & 2010,2011 & 2004,2013 \\
\hline İlkbahar & 1992,2004, & 1996,2005, & 1991,1997, \\
& 2011,2015 & 2008,2010 & 2003,2014 \\
& & & \\
\hline Yaz & 1990,1993, & 2011,2012, & 1991,2003, \\
& 1994,1996 & 2015,2016 & 2005,2006 \\
& & & \\
\hline Sonbahar & 2007,2011, & 2002,2006, & 2000,2001, \\
& 2015,2018 & 2010,2012 & 2004,2013 \\
& & & \\
\hline
\end{tabular}

\subsection{Metot}

\subsubsection{Weibull Dă̆ılımı}

Rüzgâr potansiyelinin hesaplanmasında en çok kullanılan istatiksel dağılım, iki parametreli Weibull dağılımıdır. İki 
parametreli Weibull dağılımı ölçek ve şekil parametrelerini barındırır. Weibull dağılımı, şekil parametresinin farklı değerleri alması durumunda farklı dağılımlara dönüşür. Şekil parametresi $\beta$ $=1$ olduğunda üstel dağ 1 lım, $\beta=2$ olduğunda Rayleigh dağılımına ve $\beta=3,4$ olduğunda normal dağılıma dönüşür.

$$
\mathrm{f}(\mathrm{v})=\frac{k}{c} \frac{v}{c}^{(k-1)} \exp \left(-\frac{v}{c}\right)^{(k)}
$$

Burada v, rüzgâr şiddetini (m/s), k ve c sırasıyla şekil ve ölçek parametrelerini temsil eder. Weibull kümülatif dağılım fonksiyonu ise

$\mathrm{f}(\mathrm{v})=1-\exp \left(-\left(\frac{v}{c}\right)^{k}\right)$

şeklinde ifade edilir. Şekil parametresi, ekvator çevresinde 1, 1lıman enlemlerde 2 ve daimi rüzgâr alanları için ise 3 civarındadır (Weisser 2003).

\subsubsection{Wind Atlas Analysis and Application Progra (WAsP)}

Wind Atlas Analysis and Application Program (WAsP) 1987 yılında Danimarka Teknik Üniversitesi (DTU) Risø National Laboratory Wind Energy and Atmospheric Physics bölümü tarafından geliştirilmiştir. WAsP rüzgâr veri analizi, rüzgâr hızı tahmini, rüzgâr atlası oluşturma, rüzgâr enerji hesaplamaları ve türbin yerleşim işlemleri, rüzgâr iklim değerlendirilmesi yapmaktadır. Ham verinin analizi sayesinde rüzgâr ölçümleri bir zaman serisi şeklinde analiz edilir. Weibull parametreleri de bu veriden hesaplanır. Rüzgâr türbinin yıllık ortalama güç eğrisi ile WAsP kullanılarak üretim değerlendirilmesi yapılabilir. WAsP rüzgâr türbinlerinden daha doğru sonuçlar için türbinlerin yerleştirilmesi gereken yerleri de verir. Rüzgâr güç potansiyelinin tahmininde ise ortalama rüzgârın toplam enerji içeriği WAsP ile hesaplanır. Türbinin yıllık ortalama güç üretiminin gerçek bir değerlendirmesi, söz konusu türbinin güç eğrisi ile WAsP' 1 kullanarak elde edilebilir. Program rüzgâr hız verilerinin iki parametreli Weibull dağılımına uygun bir dağılım gösterdiğini varsayarak veri analizini gerçekleştirir.

Çalışmada kullanılan veri setlerinin hepsinde hâkim rüzgâr yönü kuzeydoğudur. Tüm veri setlerinin Weibull dağılımındaki k parametresi, rüzgâr enerjisinde kullanılabilir aralık olarak kabul edilen 1-3 aralığındadır. Veri setleri herhangi bir düzeltme işlemine tabi tutulmamıştır. Rüzgâr verilerinde kopukluk, eksiklik söz konusu değildir. Her mevsim için, her bir fazdaki hâkim rüzgâr yönü, bu yöndeki rüzgârın yüzdesi, ortalama rüzgâr şiddeti, Weibull dağılımı k parametresi ve belirlenen konumdaki türbinin yıllık enerji üretimi hesaplanmıştır. KAS Endeksinin değerlerinin sıfırına en yakın olduğu mevsimler, nötr faz kabul edilmiştir. KAS Endeksinin negatif ve pozitif faz için hesaplanan değerleri, nötr faz için hesaplanan değerler ile karşılaştırılmıştır.

\section{Araştırma Sonuçları ve Tartışma}

\section{1. Çalışma Yerinin Tespiti}

Çanakkale için 2019 yılına ait saatlik ortalama rüzgâr şiddet ve yön verileri WASP' da kullanılarak analiz edilmiştir. 2019 yılına ait verilerden elde edilen yıllık enerji potansiyeline göre potansiyelin en yüksek olduğu bölge, WAsP programı aracılığı ile, Weibull dağılımı kullanılarak belirlenmiştir (Şekil 4). Oluşturulan haritada en yüksek potansiyele sahip $(6 \mathrm{GWh}$ ' lik potansiyelin olduğu) bölgeden bir nokta çalışmanın devamında kullanılmak üzere seçilmiştir. Seçilen noktanın koordinatları Evrensel Enlem Merkatörü (Universe Transverse Mercator (UTM)) projeksiyonuna göre 451523,5 m. Doğu ve 4440298,0 Kuzey'dir
(Şekil 4'te 1 ile gösterilen kırmızı bölge). Daha sonra her mevsimin pozitif, negatif ve nötr fazları kendi içerisinde değerlendirilmek üzere WASP' da incelenmiştir. Vestas marka V80 ( 2 MW) türbini yerleştirilmek için yukarıda seçilen koordinat kullanılmıştır. Türbin iz etkisi vb. sorunlarla karşılaşmamak ve sadece KAS' in etkisini incelemek için çalışmada tek türbin kullanılmıştır.

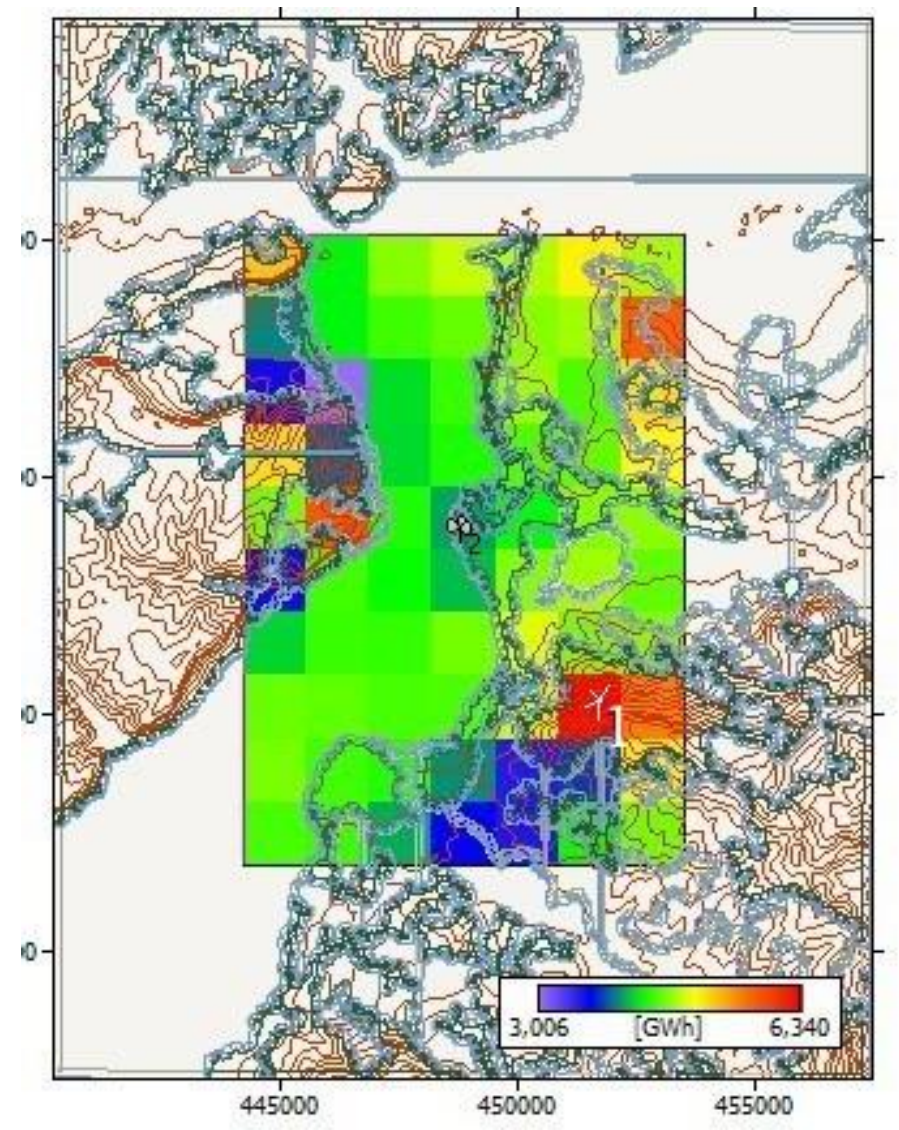

Şekil 4: 2019 Yılı verileri kullanılarak hesaplanan yıllık rüzgar enerjisi potansiyeli

\subsection{Kas Analizi}

\subsubsection{Kış mevsimi}

Kış mevsiminde KAS sınıfları için rüzgâr istatistikleri ve enerji üretimi değerleri Tablo 2'de gösterilmiştir. Nötr kışlar için veri setinde rüzgârların \% 39,5'lik kısmı 45 dereceden esmiştir. Nötr kışlar için ortalama rüzgâr şiddeti, $4,73 \mathrm{~m} / \mathrm{s}$ olarak hesaplanmıştır. Veri setinin Weibull dağılımında k parametresi 1,49'dur. Negatif kışlar veri setinde rüzgârların \%45,9'luk kısmı 45 dereceden esmiştir. Negatif kışlar için ortalama rüzgâr şiddeti $4.32 \mathrm{~m} / \mathrm{s}$ 'dir. Veri setinin Weibull dağılımında k parametresi 1,51'dir. Pozitif KAS fazı için kış mevsimine ait rüzgârların \%47,6'lık kısmı 45 dereceden esmiştir. Ortalama rüzgâr şiddeti $3.96 \mathrm{~m} / \mathrm{s}$ olarak hesaplanmıştır. Veri setinin Weibull dağılımında $\mathrm{k}$ parametresi $1,38^{\prime}$ dir.

Negatif ve pozitif kışlar nötr kışlarla kıyaslandığında; hâkim rüzgâr yönünde bir değişiklik olmadığı görülmüştür. Pozitif kışlarda, kuzey batıdan esen rüzgârların frekansında artış olmuştur. Negatif kışlarda, ortalama rüzgâr şiddeti, \%8,6 azalırken; pozitif kışlarda \%16 azalmıştır. Weibull dağılımının k parametresinin değişimine baktığımızda; negatif kışlarda bir değişiklik gözlemlenmez iken pozitif kışlarda \%7'lik bir azalma gözlenmektedir. Üretim değerlerine baktığımızda, nötr kışlar için 
yıllık üretim 8,225 Gwh, negatif kışlar için yıllık üretim 8,2 Gwh, pozitif kışlar için yıllık üretim 7,032 Gwh' dir. Üretim değerleri; negatif kışlar için değişmez iken pozitif kışlar için yaklaşık \%15 oranında azalmıştır

Tablo 2. Klş mevsimi için KAS sınıflarına göre rüzgâr istatistikleri ve enerji üretimi

\begin{tabular}{l|c|c|c|c|c}
\hline & $\begin{array}{c}\text { Hâkim Rüzgâr } \\
\text { Yönü }\end{array}$ & Veri Yüzdesi & $\begin{array}{c}\text { Ortalama Rüzgâr } \\
\text { Şiddeti (m/s) }\end{array}$ & $\begin{array}{c}\text { Weibull k } \\
\text { Parametresi }\end{array}$ & Enerji Üretimi (GWh) \\
\hline Nötr KAS & 45 & 39,5 & 4,73 & 1,49 & 8,225 \\
\hline Negatif KAS & 45 & 45,9 & 4,32 & 1,51 & 8,2 \\
\hline Pozitif KAS & 45 & 47,6 & 3,96 & 1,38 & 7,032 \\
\hline
\end{tabular}

\subsection{2 İlkbahar mevsimi}

İlkbahar mevsiminde KAS kategorileri için rüzgâr istatistikleri ve enerji üretimi değerleri Tablo 3'de gösterilmiştir. Nötr ilkbahar veri setinin \% 42,6’lık kısmı 45 dereceden esmiştir. Ortalama rüzgâr şiddeti $3,88 \mathrm{~m} / \mathrm{s}$ olarak hesaplanmıştır. Veri setinin Weibull dağllımında $\mathrm{k}$ parametresi 1,65 'dir. Negatif ilkbaharlar veri setinin \%35,6'lık kısmı 45 dereceden esmiştir. Ortalama rüzgâr şiddeti $3,48 \mathrm{~m} / \mathrm{s}$ olarak hesaplanmıştır. Veri setinin Weibull dağılımında $\mathrm{k}$ parametresi 1,51'dir. Pozitif ilkbahar veri setinin \%40,3'lük kısmı 45 dereceden esmiştir. Ortalama rüzgâr şiddeti $4,00 \mathrm{~m} / \mathrm{s}$ olarak hesaplanmıştır. Veri setinin Weibull dağılımında $\mathrm{k}$ parametresi 1,71'dir.
Negatif ve pozitif ilkbaharlar nötr ilkbaharlarla kıyaslandığında; hâkim rüzgâr yönünde bir değişiklik olmadığı görülmüştür. Negatif ilkbaharlarda, güney batıdan esen rüzgârların frekansında artış olmuştur. Negatif ilkbaharlarda ortalama rüzgâr şiddeti \%10,3 azalırken; pozitif ilkbaharlarda ortalama rüzgâr şiddeti $\% 3$ artmaktadır. Weibull dağılımının $\mathrm{k}$ parametresinin değişimine baktığımızda; negatif ilkbaharlarda $\% 8$ 'lik azalma var iken pozitif ilkbaharlarda \%3'luk bir artış gözlenmektedir. Üretim değerlerine baktığımızda nötr ilkbaharlar için y1llık üretim 7,164 Gwh, negatif ilkbaharlar için yıllık üretim 5,882 Gwh, pozitif ilkbaharlar için yıllık üretim 7,547 Gwh' dir. Negatif ilkbaharlarda üretim değeri \%17,9 azalmaktadır. Pozitif ilkbaharlarda ise üretim değeri $\% 5$ artmaktadır.

Tablo 3. İlkbahar mevsimi için KAS sinıflarına göre rüzgâr istatistikleri ve enerji üretimi

\begin{tabular}{l|c|c|c|c|c}
\hline & $\begin{array}{c}\text { Hâkim Rüzgâr } \\
\text { Yönü }\end{array}$ & Veri Yüzdesi & $\begin{array}{c}\text { Ortalama Rüzgâr } \\
\text { Şiddeti (m/s) }\end{array}$ & $\begin{array}{c}\text { Weibull k } \\
\text { Parametresi }\end{array}$ & Enerji Üretimi (GWh) \\
\hline Nötr KAS & 45 & 42,6 & 3,88 & 1,65 & 7,164 \\
\hline Negatif KAS & 45 & 35,6 & 3,48 & 1,51 & 5,882 \\
\hline Pozitif KAS & 45 & 40,3 & 4,00 & 1,71 & 7,547 \\
\hline
\end{tabular}

\subsubsection{Yaz mevsimi}

Yaz mevsiminde KAS kategorileri için rüzgâr istatistikleri ve enerji üretimi değerleri Tablo 4'de gösterilmiştir. Nötr yaz veri setinin \% 47,2'lik kısmı 45 dereceden esmiştir. Ortalama rüzgâr şiddeti $3,46 \mathrm{~m} / \mathrm{s}$ olarak hesaplanmıştır. Veri setinin Weibull dağılımında k parametresi 1,89 'dur. Negatif yaz veri setinin \%61,2'lik kısmı 45 dereceden esmiştir. Ortalama rüzgâr şiddeti $3,5 \mathrm{~m} / \mathrm{s}$ olarak hesaplanmıştır. Veri setinin Weibull dağılımında $\mathrm{k}$ parametresi 2,07'dir. Pozitif yaz veri setinin\%53,8'lik kısm1 45 dereceden esmiştir. Ortalama rüzgâr şiddeti $3,84 \mathrm{~m} / \mathrm{s}$ olarak hesaplanmıştır. Veri setinin Weibull dağılımında $\mathrm{k}$ parametresi 2,11'dir.
Negatif ve pozitif yazlar nötr yazlarla kıyaslandığında; hâkim rüzgâr yönünde bir değişiklik olmadığ görülmüştür. Pozitif yazlarda, kuzeyden esen rüzgârların frekansında artış olmuştur. Negatif yazlarda ortalama rüzgâr şiddeti değişmemiştir; pozitif yazlarda ortalama rüzgâr şiddeti \%10,9 artmaktadır. Weibull dağılımının $\mathrm{k}$ parametresinin değişimine baktığımızda; negatif yazlarda $\% 9,5^{\prime}$ lik ve pozitif yazlarda \%11,6'lık artış gözlenmektedir. Üretim değerlerine baktığımızda nötr yazlar için yıllık üretim 6,638 Gwh, negatif yazlar için yıllık üretim 7,665 Gwh, pozitif yazlar için yıllık üretim 8,124 Gwh' dir. Negatif yazlarda üretim değeri $\% 15,4$ ve pozitif yazlarda üretim değeri $\% 22,3$ artmaktadır.

Tablo 4. Yaz mevsimi için KAS sınıflarına göre rüzgâr istatistikleri ve enerji üretimi

\begin{tabular}{l|c|c|c|c|c}
\hline & $\begin{array}{c}\text { Hâkim Rüzgâr } \\
\text { Yönü }\end{array}$ & Veri Yüzdesi & $\begin{array}{c}\text { Ortalama Rüzgâr } \\
\text { Şiddeti (m/s) }\end{array}$ & $\begin{array}{c}\text { Weibull k } \\
\text { Parametresi }\end{array}$ & Enerji Üretimi (GWh) \\
\hline Nötr KAS & 45 & 47,2 & 3,46 & 1,89 & 6,638 \\
\hline Negatif KAS & 45 & 61,2 & 3,5 & 2,07 & 7,665 \\
\hline Pozitif KAS & 45 & 53,8 & 3,84 & 2,11 & 8,124 \\
\hline
\end{tabular}




\subsubsection{Sonbahar mevsimi}

Sonbahar mevsiminde KAS kategorileri için rüzgâr istatistikleri ve enerji üretimi değerleri Tablo 5 'de gösterilmiştir. Nötr sonbahar veri setinin \%37'lik kısmı 45 dereceden esmiştir. Ortalama rüzgâr şiddeti $3,86 \mathrm{~m} / \mathrm{s}$ olarak hesaplanmıştır. Veri setinin Weibull dağllımında $\mathrm{k}$ parametresi 1,52 'dir. Negatif sonbahar veri setinin 48,4'lük kısmı 45 dereceden esmiştir. Ortalama rüzgâr şiddeti $3,48 \mathrm{~m} / \mathrm{s}$ olarak hesaplanmıştır. Veri setinin Weibull dağılımında $\mathrm{k}$ parametresi 1,36 'dır. Pozitif sonbahar veri setinin\%56,6'llk kısmı 45 dereceden esmiştir. Ortalama rüzgâr şiddeti $3,52 \mathrm{~m} / \mathrm{s}$ olarak hesaplanmıştır. Veri setinin Weibull dağılımında k parametresi 1,68 'dir.

Negatif ve pozitif sonbaharlar nötr sonbaharlarla kıyaslandığında; hâkim rüzgâr yönünde bir değişiklik olmadığı görülmüştür. Negatif ve pozitif sonbaharlarda, (hâkim rüzgâr yönü) kuzeydoğudan esen rüzgârların frekansında artış olmuştur. Negatif sonbaharlarda ortalama rüzgâr şiddeti $\% 9,8$ ve pozitif sonbaharlarda ortalama rüzgâr şiddeti \% 8,8 azalmaktadır. Weibull dağılımının $\mathrm{k}$ parametresinin değişimine baktığımızda; negatif sonbaharlarda \% $10,5^{\prime}$ lik azalma var iken pozitif sonbaharlarda $\% 10,5^{\prime}$ lik bir artış gözlenmektedir. Üretim değerlerine baktığımızda nötr sonbaharlar için yıllık üretim $6,71 \mathrm{Gwh}$, negatif sonbaharlar için yıllık üretim 6,193 Gwh, pozitif sonbaharlar için ylllık üretim 7,291 Gwh’ dir. Negatif sonbaharlarda üretim değeri $\% 7,7$ azalmaktadır. Pozitif sonbaharlarda ise üretim değeri \%8,6 artmaktadir.

Tablo 5. Sonbahar mevsimi için KAS sinfflarına göre rüzgâr istatistikleri ve enerji üretimi

\begin{tabular}{l|c|c|c|c|c}
\hline & $\begin{array}{c}\text { Hâkim Rüzgâr } \\
\text { Yönü }\end{array}$ & Veri Yüzdesi & $\begin{array}{c}\text { Ortalama Rüzgâr } \\
\text { Şiddeti (m/s) }\end{array}$ & $\begin{array}{c}\text { Weibull k } \\
\text { Parametresi }\end{array}$ & Enerji Üretimi (GWh) \\
\hline Nötr KAS & 45 & 37 & 3,86 & 1,52 & 6,71 \\
\hline Negatif KAS & 45 & 48,4 & 3,48 & 1,36 & 6,193 \\
\hline Pozitif KAS & 45 & 56,6 & 3,52 & 1,68 & 7,291 \\
\hline
\end{tabular}

\subsection{KAS değerleri ile rüzgar şiddeti arasındaki ilişkinin incelenmesi}

Bu bölümde, her bir mevsim için en kuvvetli nötr, negatif ve pozitif KAS fazına sahip yıllarda, KAS ile yıllık ortalama rüzgar şiddeti arasındaki korelasyon incelenmiştir.

Nötr kışların rüzgar hızlarının KAS endeksleri ile arasındaki spearman korelasyon katsayısı 0,25 'dir. Aralarındaki ilişki çok zayıftır. Negatif kışların rüzgar hızlarının KAS endeksleri ile arasındaki korelasyon katsayısı $-0,43$ 'dür. Aralarındaki ilişki zayıftır. Pozitif kışların rüzgar hızlarının KAS endeksleri ile aralarındaki korelasyon katsayısı $-0,86$ 'dır. Aralarındaki ilişki yüksektir.

Nötr ilkbahar rüzgar hızlarının KAS endeksleri ile aralarındaki korelasyon katsayısı $-0,24$ 'dür. Aralarındaki ilişki çok zayıftır. Negatif ilkbahar rüzgar hızlarının KAS endeksleri ile aralarındaki korelasyon katsayısı 0,11'dir. Aralarındaki ilişki çok zayıftır. Pozitif ilkbahar rüzgar hızlarının KAS endeksleri ile korelasyon katsayısı -0,28'dir. Aralarındaki ilişki zayıftır.

Nötr yaz rüzgar hızlarının KAS endeksleri ile aralarındaki korelasyon katsayısı $-0,80$ 'dir. Aralarındaki ilişki yüksektir. Negatif yaz rüzgar hızlarının KAS endeksleri ile aralarındaki korelasyon katsayısı $-0,2$ 'dir. Aralarındaki ilişki çok zayıftır. Pozitif yaz rüzgar hızlarının KAS endeksleri ile aralarındaki korelasyon katsayısı -0,95'dir. Aralarındaki ilişki çok yüksektir.

Nötr sonbahar rüzgar hızlarının KAS endeksleri ile aralarındaki korelasyon katsayısı -0,21'dir. Aralarındaki ilişki çok zayıftır. Negatif sonbahar rüzgar hızlarını KAS endeksleri ile aralarındaki korelasyon katsayısı 0,14 'dür. Aralarındaki ilişki çok zayıftır. Pozitif sonbahar rüzgar hızlarının KAS endeksleri ile aralarındaki korelasyon katsayısı 0,36 'dır. Aralarındaki ilişki zayiftır.

\section{Sonuç}

1990-2019 yılları arasındaki Çanakkale rüzgar verileri KAS endeksi baz alınarak belirlenmiştir. Verilerin WAsP aracılığıyla değerlendirilmesi sonucunda; KAS'ın rüzgâr enerji potansiyeline etkisinin de diğer meteorolojik parametrelerde olduğu gibi mevsimsel olarak değiştiği görülmektedir. Ülkemizde KAS'in en etkili olduğu mevsim kıştır. Kış mevsiminde KAS endeksinin pozitif fazı hâkim iken ortalama rüzgâr ve yıllık üretim değeri nötr ve negatif faza göre düşüktür. Kış mevsiminde rüzgâr enerji potansiyeli için nötr ve negatif faz arasında belirgin bir değişim söz konusu değildir. İlkbahar mevsiminde ise KAS endeksinin negatif fazı etkin iken ortalama rüzgâr ve yıllık üretim değerinde belirgin düşüş söz konusudur. İlkbahar Mevsiminde KAS endeksinin pozitif fazı etkin iken ortalama rüzgâr hızında ve yıllık üretim değerinde artı̧s söz konusudur lakin artı̧̧ miktarı endeksin negatif fazına dayalı düşüş kadar yüksek değildir. KAS'ın etkisi yaz mevsiminde ülkemiz için asgari düzeydedir, bu durum rüzgâr enerjisinde de kendisini göstermektedir. Yaz mevsimi için KAS endeksinin negatif ve pozitif olduğu iki durumda da ortalama rüzgâr ve yıllık üretim değeri nötr durumdan fazladır. Nihayetinde KAS endeksinin yaz mevsiminde rüzgâr enerjisine bir etkisi yoktur. Sonbahar mevsiminde KAS endeksinin pozitif olduğu durumda yıllık üretim miktarı azami düzeyde, negatif sonbaharlar için yıllık üretim miktarı nötr faza göre düşüktür. Sonbahar mevsimi için KAS endeksinin pozitif, tarafsız ve negatif fazlarında üretim miktarında pozitiften negatife doğru belirgin bir azalma söz konusudur.

Çanakkale'nin konumu göz önüne alındığında, her mevsim farklı şekilde, rüzgâr enerji potansiyelinin $\% 5, \% 10, \% 15$ gibi oldukça yüksek oranlarda KAS'ın fazlarından etkilenmesi beklenen bir sonuçtur. Lakin sonbahar ve kış mevsiminin KAS endeksinin aynı fazlarından aynı eğilimde etkilenmemeleri çalışmanın şaşırtıcı sonuçlarındandır. Üstelik sonbahar ve ilkbahar mevsimlerinin KAS endeksinin aynı fazlarından, aynı eğilimde etkilenmeleri de çalışmanın bir diğer şaşırtıcı sonucudur. 
Sonbaharda başlayan eğilimin kış mevsiminde devam etmemesi; kış mevsiminde başlayan eğilimin ilkbaharda devam etmemesi de bir diğer şaşırtıcı sonuçtur. Yaz mevsiminde etkinin asgari düzeyden ziyade hiç olmaması da şaşırtıcıdır. KAS'ın Çanakkale rüzgâr enerji potansiyeline etkisini incelerken meteorolojik ölçüm rüzgâr verisi yerine Çanakkale de kurulu bulunan rüzgâr türbininden alınan mevsimsel üretim değerleri kullanılması daha hassas sonuçlar elde etmemize imkân tanıyacaktır. \%5, \%10, \%15 gibi rüzgâr enerji potansiyelindeki büyük oranlardaki değişim, rüzgâr enerjisinden elektrik üreten rüzgâr çiftlikleri için oldukça önemli ve anlamlı değerlerdir. Mevsimsel elektrik üretimi tahminlerinde KAS endeksinin fazlarının da tahmine dâhil edilmesi rüzgâr enerjisinden elektrik üreticileri için büyük bir kazanç olacaktır.

KAS fazları ile mevsimlik ortalama rüzgar şiddeti değerleri arasındaki ilişki incelendiğinde, yüksek negatifkorelasyon değerlerinin pozitif kış ile pozitif ve negatif yaz dönemlerinde olduğu görülmüştür. Pozitif kış aylarında görülen bu yüksek negatif korelasyon, KAS şiddeti arttıkça ortalama rüzgar şiddetinin azaldığını ifade etmekte olup, Zubiate ve ark. (2016)'nın sonuçları ile uyumludur. Daha uzun bir süre için ilişkinin incelenmesi daha iyi sonuçlar verecektir.

\section{Teşekkür}

Yazarlar, Meteoroloji Genel Müdürlüğü'ne rüzgâr verilerinin temin edilmesinden dolayı teşekkür ederler.

\section{Kaynakça}

Brayshaw, D. J., Troccoli, A., Fordham, R. \& Methven, J. (2011). The impact of large scale atmospheric circulation patterns on wind power generation and its potential predictability for UK. Renewable Energy, 36(8), 2087-2096.

García-Bustamante, E., González-Rouco, J. F., Navarro, J., Xoplaki, E., Luterbacher, J., Jiménez, P. A. Montávez, J. P., Hidalgo, A. \& Lucio-Eceiza E. E. (2013). Relationship between wind power production and North Atlantic atmospheric circulation over the northeastern Iberian Peninsula. Climate Dynamics, 40, 935-949.

Efe, B., Mentes, S., Unal, Y., Tan, E.,Unal, E., Ozdemir, E.T., Barutçu, B., Onol, B. \& Topcu, S. (2012). $72 \mathrm{hr}$ forecast of wind power in Manisa, Turkey by using the WRF model coupled to WindSim. Proceedings of the International conference on renewable energy research and applications (ICRERA '12) 2012, pp. 1-6.

Efe, B., Lupo, A. R. \& Deniz. A. (2019). The Relationship Between Atmospheric Blocking and Precipitation Changes in Turkey between 1977 - 2016. Theoretical and Applied Climatology, 138(3), 1573 - 1590.

Efe, B., Lupo, A. R., Sezen, I. \& Deniz. A. (2020). The Relationship Between Atmospheric Blocking and Temperature Anomalies in Turkey between 1977 - 2016. International Journal of Climatology, 40(2), 1022 - 1037.

EIGM (2020) https://eigm.gov.tr/tr-TR/Sayfalar/REPA, alındığ1 tarih: 30/03/2020.

IEA (2013) World Energy Outlook, 2013. https://www.eia.gov/, alındığ 1 tarih:10/03/2020.
IEA (2018) World Energy Outlook, 2018. https://www.eia.gov/, alındığ 1 tarih: 10/03/2020.

IPCC (2013) İklim değişikliği raporu, 2013. https://www.ipcc.ch/reports/, alındığ 1 tarih: 25/02/2020

Karabulut, Y. (1999). Enerji kaynaklarl, Ankara Üniv. Basımevi, ANKARA.

Klink, K. (2007). Atmospheric circulation effects on wind speed variability at turbine height. Journal of Applied Meteorology and Climatology, 46, 445-456.

NSCU (2020) https://climate.ncsu.edu/edu/NAO, alındığ1 tarih: $10 / 10 / 2020$.

NOAA (2020), https:// ncep.noaa.gov/products/precip/CWlink/ pna/nao.shtml, alındığ tarih:05/02/2020

Özdemir, E.T., Yerli, B., Efe, B., Kaymak, M.K., Sezen, İ. \& Şahin, A.D. (2013). Çatalca meteoroloji radarı çevresinde rüzgâr enerji santrali kurulumu için RETScreen ve HOMER enerji modelleri kullanılarak gerçekleştirilen fizibilite analizi. 6th Atmospheric Science Symposium, April 24 - 26, 2013, İstanbul, Turkey.

Sailor, D. J., Hu, T., Li, X. \& Rosen, J. N. (2000) A neural network approach to local downscaling of GCM output for assessing wind power implications of climate change. Renewable Energy, 19(3), 359-378.

TUREB (2019). Rüzgâr enerjisi istatistik raporu, 2018. https://tureb.com.tr//lib/uploads/73691c95373216fb.pdf, alındığg tarih: 29.08.2020.

Türkeş, M. \& Erlat, E. (2003) Precipitation changes and variability in Turkey linked to the North Atlantic oscillation during the period 1930-2000. Royal Meteorological Society, 23(14), 1771-1796.

Türkeş, M. \& Deniz Acar, Z. (2011). Güney marmara bölümü’nün (kuzey batı anadolu) klimatolojisi ile yağış ve akım dizilerinde gözlenen değişimler ve eğilimler. Uluslararası Insan Bilimleri Dergisi, 8(1), 1579-1600.

Türkiye Enerji Atlası (2020). https://www.enerjiatlasi.com/, alındığ 1 tarih: 10/03/2020.

Türkiye Rehberi (2020). https://www.turkiyerehberi.net/harita/resim/Turkiye/canakkale_haritasi.png, alındığ 1 tarih: 10/10/2020.

Wallace, J. M., \& D. S. Gutzler (1981) Teleconnections in the geopotential height field during the northern hemisphere winter. Monthly Weather Review, 109, 784-812.

Weisser, D. (2003). A wind energy analysis of Grenada: an estimation using the 'Weibull' density function. Renewable Energy, 28, 1803-12.

Yetmen, H.Y. (2006) GAP alanında kuzey atlantik salınımı'na bağlı yağış ve akım değişimleri (Yüksek Lisans Tezi). Ankara Üniversitesi.

Zubiate, L., McDermott, F., Sweeneyd, C. \& O’Malleye, M. (2017) Spatial variability in winter NAO-wind speed relationships in western Europe linked to concomitant states of the East Atlantic and Scandinavian patterns. Royal Meteorological Society, 143(702), 552-562. 